\title{
1. Introduction: regulating e-cigarettes in the face of uncertainty
}

\section{Lukasz Gruszczynski}

\section{THE CONTROVERSY OVER E-CIGARETTES}

Electronic cigarettes (e-cigarettes) are as bad for your health as conventional tobacco products. Although their vapor does not contain tar, carbon monoxide, hydrogen cyanide, or many of the other dangerous substances present in tobacco smoke, it delivers equally hazardous chemicals (for example diacetyl, cinnamaldehyde, or the notorious formaldehyde) that may cause cancer and other serious diseases. So if you are a smoker, switching to e-cigarettes makes very little sense. And e-cigarettes do not help you to quit smoking. Actually, they preserve the nicotine addiction, thus making complete cessation even more difficult. E-cigarettes also attract a lot of new users, particularly among kids and adolescents. They are fashionable (as were cigarettes many years ago) and are frequently marketed (absolutely falsely!) as a safer alternative to traditional tobacco products. The availability of these products on the market thus seriously undermines the decades of efforts on the part of the health community to eradicate the tobacco epidemic. In short, they are a wolf in sheep's clothing.

But wait a minute: maybe the truth is just the opposite. E-cigarettes, although not entirely safe, are much less harmful than conventional tobacco products. They do contain nicotine, but the overall level of other hazardous substances present in the vapor is much lower than that in tobacco smoke. Nicotine as such, although addictive, poses only limited health risks as compared to other substances present in smoke. Smokers, at least those who are unable or unwilling to quit, will therefore greatly benefit from switching to these less risky products. Actually, some of them may, thanks to e-cigarettes, eventually quit the addiction. The availability of different vapor products, including a great variety of e-liquids, is more of an incentive for current smokers to switch than a hook for kids to start smoking. Overall, e-cigarettes should be seen as part of the solution, rather than a contributing factor, to the tobacco problem. 
A quick review of recently published articles by more or less reputable news outlets in the general press confirms the ambiguous nature of reporting on e-cigarettes. Good evidence is offered from merely glancing at their titles. Thus, USA Today announces: "Depression, anxiety, nicotine withdrawal: Trying to quit vaping "was hell'," while The Lantern states "Safe smoking alternative e-cigarette revealed as dangerous and addictive." In a similar fashion, The Sun warns that "Vapers [are] 'at risk of irreversible popcorn lung' if they puff on flavoured e-cigarettes,"3 while Eugene Weekly has no doubt that "E-cigarettes hook a new generation of teens." ${ }^{4}$ On the other hand, CNN explains that "E-cigarettes [are] less toxic to users than cigarettes," while The Sun later surprisingly claims: "Vaping isn't as bad as you think! Deluded smokers 'risk lives' by refusing to switch to e-cigarettes." The Conversation also optimistically informs the reader that "Smokers who switch could be less likely to use cigarettes again." "Of course, one may downplay the significance of these differences. At the end of the day, news outlets tend to oversimplify their messages and frequently play with the titles of articles to attract the attention of potential readers. But the opposing opinions about the potential risks and benefits of e-cigarettes also deeply divide the community of scientific experts.

Some specialists, for example, confirm that e-cigarettes pose their own health risks resulting from nicotine inhalation or chronic inhalation of other toxicants present in the vapor. ${ }^{8}$ The most important limitation of this line

J. O’Donnell, "Depression, anxiety, nicotine withdrawal: Trying to quit vaping 'was hell'" (USA Today, December 27, 2018) https://bit.ly/2AvuS4B accessed January 15, 2019.

2 K. Hamilton, "Safe smoking alternative e-cigarette revealed as dangerous and addictive" (The Lantern, January 1, 2019) https://bit.ly/2F8wR2L accessed January 15, 2019.

3 A. Downey, "Vapers 'at risk of irreversible popcorn lung' if they puff on flavoured e-cigarettes" (The Sun, November 20, 2018) https://bit.ly/2GT8hV2 accessed January 15, 2019.

4 C. Cruzan Morton, "E-cigarettes hook a new generation of teens" (Eugene Weekly, January 3, 2019) https://bit.ly/2AtRsdW accessed January 15, 2019.

5 N. Thomas, "E-cigarettes less toxic to users than cigarettes, study says" (CNN, December 14, 2018), https://cnn.it/2GjSUES accessed January 15, 2019.

6 M. Larbi, "Vaping isn't as bad as you think! Deluded smokers 'risk lives' by refusing to switch to e-cigarettes, experts say" (The Sun, January 4, 2019) https://bit.ly/ 2GW61v1 accessed January 15, 2019.

7 M. Klonizakis, "Smokers who switch could be less likely to use cigarettes again" (The Conversation, January 3, 2019) https://bit.ly/2Aud4Hc accessed January 15, 2019.

8 For a detailed review of the available scientific evidence (and respective reference sources) behind the different claims presented here, see particularly Chapters 2 and 3 of this volume. Other chapters also refer extensively to various scientific data. 
of reasoning - as its opponents point out - is the lack of contextualization. Although the level of some toxicants in aerosol may be as high as those in tobacco smoke, and while nicotine is not as harmless as some argue, overall the use of these products is connected with a much lower risk exposure than is the case with conventional cigarettes. A well-known report commissioned by Public Health England estimated, for example, that e-cigarettes are around 95 percent safer than smoked tobacco. ${ }^{9}$

There are also researchers who highlight our limited knowledge about e-cigarettes and the long-term health consequences of their use. In this context, they stress that their real impact can be verified only on the basis of comprehensive observations that will take decades to collect (owing to the lengthy lag time for the onset of many smoking-related diseases, such as cancer or emphysema). Others suggest that the use of e-cigarettes can preserve the nicotine addiction and prevent smokers from quitting completely. The efficacy of e-cigarettes as a cessation device has been questioned by many experts. It has also been argued that e-cigarettes may serve as a gateway for adolescents and kids to conventional smoking (the so-called gateway effect) or renormalize smoking by helping to make it socially acceptable behavior once again.

On the other hand, a considerable group of health experts seem to be confident that the available scientific data allow for the conclusion that e-cigarettes are much safer than traditional tobacco products. Although they admit the existence of uncertainties about their long-term health effects, they also accentuate that those uncertainties should be seen against the benchmark scenario of perpetuated use of combustible tobacco products. Some researchers also question the gateway and renormalization hypotheses, highlighting different methodological limitations in the underlying scientific studies. Finally, there are those who argue that e-cigarettes can be an effective cessation device, and others who concentrate more on their harm reduction dimension - that is, irrespective of whether e-cigarettes can help quit the nicotine addition, they present a safer and more realistic alternative to conventional smoking for those users who are unable or unwilling to quit.

\section{E-CIGARETTES AS A SUBJECT OF REGULATION}

Considering the disagreement in the scientific community, it is not surprising to see widely divergent regulatory approaches to e-cigarettes around the globe. In the absence of compelling science that would support a particular type of

9 A. McNeill et al, E-cigarettes: An Evidence Update (A Report Commissioned by Public Health England, Public Health England 2015) 6. 
policy, regulators in various jurisdictions are taking different positions with equal justification. The result is that a broad array of policy interventions are currently in effect. In particular, countries may classify e-cigarettes as: (i) tobacco products, derivatives, or substitutes (for example Azerbaijan, Costa Rica, Georgia, Honduras, and South Korea); ${ }^{10}$ (ii) products imitating tobacco (for example Colombia and Mexico); (iii) medicinal or pharmaceutical products, at least for those e-cigarettes that come with therapeutic claims (for example Chile, the European Union (EU), and Japan); ${ }^{11}$ (iv) consumer products (for example Armenia, Bosnia and Herzegovina, China, and Russia); ${ }^{12}$ (v) poisons (for example Australia, with regard to e-liquids containing nicotine) ${ }^{13}$ or (vi) a sui generis category (for example Ecuador, Canada, the EU, Moldova, and New Zealand). In some places, e-cigarettes are simply banned-sometimes not only their sale but also their personal importation and possession (for example in Argentina, Brazil, Gambia, Egypt, some Indian states, Jordan, Philippines, Singapore, Thailand, Taiwan, the United Arab Emirates, Uruguay, and Vietnam). ${ }^{14}$ Overall, there are 101 countries that do not have any specific regulations for e-cigarettes (treating them as a regular consumer good) and 39 which ban their sale, while the remaining group, which includes most of the developed nations, regulates them in a variety of other ways. ${ }^{15}$ In terms of the legal mechanisms applied, countries have either reinterpreted or amended existing regulations to cover e-cigarettes, adopted new laws, or used some mixture of these two methods. ${ }^{16}$

Different rules will apply depending on the classification of e-cigarettes. Treating e-cigarettes as products imitating tobacco or poison leads in most of the jurisdictions to a ban on their sale, while qualifying them as an ordinary consumer good only subjects them to existing general product safety and liability regimes, and in in general does not affect their availability on the market. A considerable group of countries treat e-cigarettes as medicinal or pharmaceutical products. This means that before they are placed on the market, they

10 All information on specific national regulatory regimes are based on data provided by the Global Tobacco Control database https://globaltobaccocontrol.org accessed January 15, 2019.

11 For further details on the EU regime see Chapters 7 and 8 in this volume.

12 For further details on the Chinese regulatory approach see Chapter 9 in this volume.

13 For an in-depth discussion on the Australian legal regime for e-cigarettes see Chapter 11 in this volume.

${ }_{14}$ For further analysis of the Taiwanese approach see Chapter 9 in this volume.

15 H. Shapiro, No Fire, No Smoke: The Global State of Tobacco Harm Reduction 2018 (Knowledge-Action-Change 2018) 84.

16 R.D. Kennedy et al, "Global approaches to regulating electronic cigarettes" (2017) 26 Tob Control 440. 
need to go through a thorough and demanding authorization process, which sometimes includes a requirement of clinical trials. As yet, no e-cigarette has been registered as a medicinal/pharmaceutical device, ${ }^{17}$ so in practice such a classification has the same effect as a complete sales ban. E-cigarettes may be also placed in two or possibly more categories in a single jurisdiction. For example, e-cigarettes featuring cessation claims can be classified as medicinal products; those without such claims may be classified either as a poison, consumer good, or sui generis category; and e-cigarettes imitating tobacco products may be completely prohibited.

So far, no consensus has emerged at the international level. The Conference of the Parties (COP) of the World Health Organization's (WHO) Framework Convention on Tobacco Control (FCTC), a major international point of reference for tobacco control standards, has only recently commenced work on this issue (owing to, inter alia, the relatively short history of e-cigarette use), and at present it remains unclear whether and to what extent the FCTC provisions are even relevant for the regulation of this category of products. ${ }^{18}$ What is clear is that the FCTC Secretariat and the COP accept a total ban on e-cigarettes as one of the legitimate regulatory options available to states. For those countries which tolerate their presence on the market, the COP has recommended-but not required - the adoption of certain control policies that closely resemble the approach taken with respect to traditional tobacco products.

\section{THE SCOPE OF THIS BOOK AND TERMINOLOGICAL CLARIFICATIONS}

This book is about the regulation of e-cigarettes. The product in question, which is also referred to in the WHO nomenclature as an "electronic nicotine delivery system" (ENDS), is a battery-powered device designed to deliver nicotine by heating a solution (the so-called e-liquid) to be inhaled by a user. Technically speaking, ENDS is a broader category that includes other similar devices such as e-shisha or e-pipes (all of them have the same mode of operation). Nevertheless, e-cigarettes are by far the most common subclass, and in this book, unless stated otherwise, both terms (ENDS and e-cigarettes) are used interchangeably. Note that the WHO and FCTC COP also use the notion of "Electronic Non-Nicotine Delivery Systems," which are basically ENDS without nicotine. In principle, this category is not covered by this book (except in Chapter 9).

17 Shapiro (n 15) 85.

18 For a detailed discussion of this issue see Chapter 4 of this volume. 
E-liquids used in e-cigarettes are composed of vegetable glycerin (VG), propylene glycol (PG), a great variety of flavorings or their mixtures (for example diacetyl, acetyl propionyl, vanillin, ethyl maltol, ethyl vanillin, or menthol), ${ }^{19}$ and nicotine, in varying concentrations. Nicotine as such can come in two different forms: freebase and nicotine salts. The form of the nicotine affects the users' experience - for example, salts allow for a higher concentration of nicotine in e-liquids, which is more easily absorbed by the human body in this form. They also decrease the harshness of vaping that is typically experienced by users who use more potent freebase e-liquids. On the other hand, nicotine salts may also pose their own health challenges, for example because of the presence of the benzoic acid normally used to formulate nicotine salts. ${ }^{20}$ Older e-liquids were predominantly based on the freebase form, while newer products increasingly use nicotine salts.

Modern e-cigarettes were invented in China in 2003 and quickly became popular. ${ }^{21}$ They were introduced into Europe and the US in 2006-7 and have gradually spread around the globe. ${ }^{22}$ The e-cigarette still remains a niche product, albeit one that is quickly gaining popularity. As of 2017 the global e-cigarette market was valued at US $\$ 13,899.9$ million; it is expected to witness an annual growth rate of almost 20 percent between 2018 and $2023 .{ }^{23}$ Various types of device are currently available on the market. Conventionally they are grouped into generational categories. The first generation, also referred to as the "cigalike," was popular about a decade ago. These e-cigarettes tended to look like combustible cigarettes and most of them came as disposable models. The second generation devices - vape pens - do not resemble traditional cigarettes. They have refillable e-liquid cartridges (allowing for a broader selection of flavors), are rechargeable, and have more powerful batteries. The third generation products ("mods") are much bigger, usually in the form of a cylinder or box, and offer a greater degree of control over a device, permitting the user to, for example, set wattage and voltage. They are refillable and rechargeable. Pod-based systems have recently become more popular. They are much smaller than mods and, in most cases, they do not look like cigarettes. They are

19 See for example C. Hutzler et al, "Chemical hazards present in liquids and vapors of electronic cigarettes" (2014) 88 Arch Toxicol 1295; P.A. Tierney et al, "Flavour chemicals in electronic cigarette fluids" (2016) 25 Tob Control e10.

20 See for example J.F. Pankow et al, "Benzene formation in electronic cigarettes" (2017) 12(3) PLoS One e0173055.

${ }^{21}$ For a detailed discussion on the various prototypes of e-cigarettes and Hon Lik's invention, see Chapter 2 in this volume.

22 M.A. Rahman et al, "Electronic cigarettes: patterns of use, health effects, use in smoking cessation and regulatory issues" (2014) 12 Tob Induc Dis 21.

23 PS Market Research, E-Cigarette Market Size, Share. Industry Analysis Report, 2023 (September 2018) https://bit.ly/2rRcUYy accessed January 15, 2019. 
composed of a pod (which is basically a coil integrated with a small tank) and a battery (stronger than a cigalike but weaker than those used in the second and third generation models). Pods can be either disposable or refillable.

There are other products on the market that are used to deliver nicotine and also are not based on the combustion of tobacco. They come under different names, such as electronically heated tobacco products; novel tobacco products; vapor products (a broad category that also includes ENDS); heat-notburn tobacco products; and electric smoking systems. With the exception of vapor products, all are based on devices that use an electric heating element to char, rather than burn, the tobacco. This requires a lower temperature, allowing for the release of nicotine in a form of aerosol (which is nevertheless regarded by some researchers as smoke ${ }^{24}$ ) without oxidization and the discharge of carbon. As a consequence, they are claimed to pose a lower risk as compared to conventional tobacco products. ${ }^{25}$ Many health specialists indicate, however, that the scientific evidence concerning the risk profile of those products is too limited to come up with any definitive conclusions, and they also worry that most of the data come from industry-funded research projects. ${ }^{26}$ This segment of the market has been dominated by the largest tobacco companies, and the two leading models are IQOS (owned by Philip Morris International Inc.) and Glo (owned by British American Tobacco Plc). None of these products is covered by this book.

It should be added that while the scope of the book is comprehensive, it does not pretend to exhaust all the relevant subject matter relating to the regulation of e-cigarettes. The selection of the chapters reflects both the aims of the editor and the research interests of the contributing authors (whose affiliations are disclosed in the Notes on Contributors at the beginning of this volume). When inviting the authors, the editor tried to ensure that they represented different viewpoints. As a consequence, there are contributors who advocate for rather lenient regulatory regimes for e-cigarettes, as well as those who would like to see much stricter regulatory models. This diversity of opinions clearly echoes

24 R. Auer et al, "Perplexing conclusions concerning heat-not-burn tobacco cigarettes - reply" (2017) 177(11) JAMA Internal Medicine 1699.

25 See for example PMI, "Creating less harmful alternatives to smoking" (PMI webpage, undated) https://bit.ly/2Hf9dSR accessed January 15, 2019.

26 See for example FCTC COP, Further Development of the Partial Guidelines for Implementation of Articles 9 and 10 of the WHO FCTC, Report by WHO, FCTC/ $\mathrm{COP} / 7 / 9$, July 12, 2016 (Conference of the Parties to the WHO Framework Convention on Tobacco Control, Seventh session, Delhi, India, November 7-12, 2016) 5-6; F. Moazed et al, "Assessment of industry data on pulmonary and immunosuppressive effects of IQOS" (2018) 27 (Suppl 1) Tob Control s20. For a different view, see McNeill et al (n 9). 
the ongoing debate in the public health, regulatory, and business communities over the optimal way to regulate e-cigarettes.

The chapters included in this book reflect the state of scientific research and the regulatory environment as of October 31, 2018. While this book is among the most up-to-date positions on the market, readers should be aware that the field is subject to dynamic changes of a scientific, legal, and market character. Some changes have already occurred between the closing date for the book and the moment of its publication, while others might be coming in the near future. A brief summary of what has happened and what may be expected is provided in the final section of this chapter.

\section{THE RESEARCH QUESTIONS, STRUCTURE, AND CONTENT OF THE BOOK}

The issues and problems surrounding ENDS regulation - at the international, European and national levels - lie at the heart of this edited volume. In particular, the contributing authors have been asked to address one or more of the following questions:

1. What are the factors that influence the choice of a particular regulatory regime by regulators at the national, supranational, and international levels?

2. What is the design of the different regulatory models for e-cigarettes introduced by regulators in specific jurisdictions? What legal problems emerge in this context?

3. What is the optimal regulatory model for the regulation of e-cigarettes? Is it possible to identify one at the current stage of scientific development?

4. What roles do the precautionary and harm reduction principles play when formulating rules applicable to e-cigarettes?

5. How do certain international (for example human rights, international trade rules, FCTC obligations) and supranational (for example EU) legal standards restrict the regulatory freedom of regulators in this policy space?

This volume has been divided into three parts. The first part ("Science, regulation and e-cigarettes") provides an up-to-date review of the current scientific research on e-cigarettes in the broader historical perspective. This part constitutes the basis for the subsequent discussions on the specific regulatory challenges that are emerging in this field. The second part ("International and European law perspectives") contains several chapters that discuss various sets of international and supranational obligations that may restrict the regulatory freedom enjoyed by individual states/supranational regulators in this area. The third and final part ("National law perspectives") presents four national case 
studies (two of them merged into one chapter) which investigate how e-cigarettes are regulated in selected jurisdictions.

The first part is composed of two chapters. It starts with a general text by Mateusz Zatoński and Allan M. Brandt ("Divide and conquer? E-cigarettes as a disruptive technology in the history of tobacco control") which looks at e-cigarettes as an example of disruptive innovation and analyzes different societal and regulatory consequences resulting from the emergence of this new technology - for example, the polarization of the tobacco control community, the implications of technology for the viability of the endgame strategy, or the relegitimization of Big Tobacco. The second chapter in this part ("Review of the scientific evidence relating to electronic cigarettes: where do we stand now?") — authored by Charlie A. Smith, Aleksandra Herbeć, and Lion Shahab - summarizes and critically assesses the current scientific knowledge on the use of e-cigarettes, particularly with regard to their safety or efficacy as a cessation or harm reduction device, as well as the strength of the gateway effect hypothesis. It concludes that there is little evidence to suggest that e-cigarettes have renormalized smoking or act as a gateway to tobacco use among adolescents. The chapter also notes that although e-cigarettes are not completely safe and further research is still needed, the evidence available thus far indicates that these products are significantly safer than conventional cigarettes. This means that they may have a positive impact on public health in the context of tobacco harm reduction strategies.

The second part of the book consists of five chapters. In the text that opens this section ("Taming Schrödinger's cat: e-cigarettes under the Framework Convention on Tobacco Control"), Lukasz Gruszczynski investigates whether and to what extent the FCTC disciplines apply to e-cigarettes and whether the mandate enjoyed by the COP is sufficiently broad to deal with these products. He concludes that due to the formulation of the relevant FCTC provisions, the complex nature of ENDS, and the unwillingness of the COP to take a decisive position on the status of these products, the Convention regime will not reduce (at least for now) the regulatory heterogeneity among the State Parties. At the same time, the chapter proposes the development of a sui generis model for e-cigarettes that takes into account not only the risks posed by their use, but also their harm reduction potential. The subsequent text by Marie Elske C. Gispen and Jacquelyn D. Veraldi- "A human rights approach to the regulation of electronic cigarettes"-looks at the legal constraints imposed by international human rights law on the regulatory freedom enjoyed by states in this policy space. The authors conclude that under general international human rights law, governments are required to actively discourage the use of harmful substances, including the nicotine which is present in e-cigarettes. This baseline scenario may however be modified in light of research into the ability of ENDS to serve as a harm reduction tool and/or gateway product. In this context, the authors 
propose various policy recommendations on appropriate regulatory responses that take into account these two aspects and at the same time respect states' international human rights obligations. The next chapter, by Marina Foltea and Bryan Mercurio ("A ban on electronic nicotine delivery systems: step one in the WTO discrimination analysis"), carries out a similar analysis under the law of the World Trade Organization (WTO) by exploring the relevant provisions for the assessment of WTO compatibility of complete sales bans imposed on e-cigarettes in a situation where traditional combustible products are available on the market. The chapter concentrates in this context on the antidiscrimination disciplines provided by the General Agreement on Tariffs and Trade and the Agreement on Technical Barriers to Trade, looking specifically at likeness analysis (e-cigarettes versus combustible tobacco). It concludes that there is a good chance that both categories may be found to be like products. This in turn may require governments, in cases of potential trade dispute, to come up with solid scientific evidence that would explain the reasons justifying discrimination between e-cigarettes and traditional tobacco products.

The last two chapters in the section concentrate on the new EU legal regime for e-cigarettes introduced by the Tobacco Products Directive (TPD). "Regulating e-cigarettes at the EU level," authored by Anna Pudło and Lukasz Gruszczynski, analyzes the legislative process that led to the adoption of the new EU regulatory framework for e-cigarettes and attempts to identify the factors that have had an impact on its ultimate shape, at the same time presenting the main features of this framework. This chapter also assesses the legality of the new regime under the relevant EU rules, taking as a point of reference the judgment of the Court of Justice of the European Union (CJEU) in the Pillbox 38 (UK) Ltd v Secretary of State for Health dispute. The authors ultimately conclude that the TPD, with its sui generis legal regime for e-cigarettes, can be seen as a realistic (albeit not perfect) compromise between the proponents and opponents of the new technology. In the next chapter ("Vaping and the precautionary principle in EU law"), Giancarlo A. Ferro and Costanza Nicolosi come to a completely different conclusion. In their opinion the TPD primarily constitutes a missed opportunity to embrace new technology for the benefit of public health. For the most part, the EU has extended to ENDS products the restrictions already in place for traditional tobacco products, even though it seems likely that the latter are much less safe than e-cigarettes. According to the authors, the reason for such a strict approach might be that the precautionary principle (which ostensibly formed the basis of the regulatory action) has, in the EU context, been transformed from a tool aimed at balancing market and public interests to an instrument to further harmonize the EU internal market. They also note that the precautionary principle cannot be seen as compelling any specific regulatory model for e-cigarettes. It only provides a 
legal basis for such regulation; it does not require any regulatory actions to be taken. In the end, a relevant decision remains a political one.

The last part of the book includes three chapters that analyze the approaches taken by regulators in selected jurisdictions (Taiwan, China, the United States, and Australia). The choice of these particular countries is not accidental. They were selected not only to ensure the broad geographical diversity of the book, but also because these countries have opted for different regulatory models: a total ban on e-cigarette sales; a laissez-faire approach; and a tobacco control regime. Taking these together with the two chapters that analyze the EU sui generis model, the book therefore provides a good overview of the various regulatory approaches to e-cigarettes that are taken by states. Moreover, some of the analyzed countries are leaders in tobacco control policies, and they often set standards that are subsequently adopted by the rest of the world. China is a notable exception here, but it is also one of the biggest markets for e-cigarettes and the main producer of such devices.

The first chapter in this section ("E-cigarette regulation in Taiwan and China"), authored by Chuan-Feng Wu, Ching-Fu Lin, and Mao-Wei Lo, analyzes the regulatory approach to e-cigarettes in Taiwan and China (with a focus on Taiwan). The authors see the emergence of e-cigarettes primarily as a challenge rather than an opportunity for the Taiwanese regulators (for example due to the growing popularity of e-cigarettes among younger consumers). In this context, they examine the existing provisions that regulate e-cigarettes in Taiwan and China and come to the conclusion that neither of the countries provide an optimal model. In the case of Taiwan they call for a single integrated model (rather than a two track system) that incorporates elements of both the pharmaceutical regime and the comprehensive ban. As far as China is concerned, their proposal is more modest, as it only postulates a set of basic rules and standards for product safety, nicotine limits, and health controls. In her chapter, Patricia I. Kovacevic ("Regulation of e-cigarettes in US law") takes a completely different position. Although she also argues that the current legislative framework for ENDS in the US is substantially inadequate (and internally inconsistent), for her the real problem lies in the fact that the relevant framework does not differentiate ENDS from cigarettes, does not acknowledge the risk differential between tobacco products and ENDS, and places a much higher - and economically unsustainable - regulatory burden on the fledgling ENDS industry than it does on the conventional cigarette industry. As a consequence - and coupled with spotty enforcement and unfair competition on the marketplace from illicit ENDS and other types of recreational products- the US regulatory regime does not at present create a transparent and consistent tobacco harm reduction environment. In this context, Kovacevic calls for the engagement of Congress through revisiting the US Tobacco Control Act to take into account the beneficial position of ENDS on the nicotine risk con- 
tinuum, while imposing safeguards regarding product design and responsible communications to various audiences.

The final chapter looks at the Australian regulatory approach to e-cigarettes ("One does not simply sell e-cigarettes in Australia: an overview of Australian e-cigarette regulations"). The authors, Coral Gartner and Marilyn Bromberg, note that the Australian laws concerning e-cigarettes are complex and have been inconsistently interpreted by different jurisdictions and government ministers, while the type of enforcement action related to e-cigarettes has varied by jurisdiction. Although there have been some attempts to liberalize the very strict regulatory model currently in place, these have been met with strong opposition from various organizations, the government, and prominent public figures. According to the authors, the hostility to tobacco harm reduction is likely to have been influenced by the previous Australian experience with low tar cigarettes and an enduring distrust of and animosity toward the tobacco industry. At the same time, the authors note that there are practical and ethical issues associated with the current policy, which penalizes smokers for switching to a lower risk nicotine product, and argue that a more coherent and ethical policy approach would be to allow the legal sale of nontherapeutic nicotine-containing e-cigarette products to adults, with regulations imposed to minimize potential risks.

\section{SOME REMARKS ON THE SELECTED FINDINGS OF THE CONTRIBUTING AUTHORS}

Overall, the contributing authors have addressed all the questions put forward by the editor. Having said this, one also needs to acknowledge that while some research problems have received considerable attention, others have been tackled only at the margins of the main discussion. A careful review of the individual chapters shows both common points and areas of disagreement among the authors. For example, all of the authors who deal with the relevant question agree that the optimal regulatory strategy for e-cigarettes should take into account not only the risks (actual and potential) posed by e-cigarette use, but also the harm reduction potential of those products. At the same time, the authors disagree as to how this general approach should be translated into specific regulatory mechanisms. Some of them see a traditional tobacco regulatory model as appropriate, as it allows for keeping ENDS out of the reach of children and discouraging non-smokers without preventing the realization of e-cigarettes' potential as smoking cessation aids (Chapter 2). Others disagree and argue that the regulatory response should be tailored to the risks posed by these products (particularly for minors and non-smokers), without however undermining their potential to serve as a less harmful replacement for current tobacco users. This means that ENDS should be treated as a special 
category, one that is different from traditional tobacco products (Chapter 4). In this context, Pudło and Gruszczynski see the TPD, with its sui generis legal regime for e-cigarettes, as a realistic, albeit not perfect, compromise between the proponents and opponents of the new technology — one that recognizes the harm reduction potential of the products but also acknowledges the existing uncertainties resulting from the gaps in knowledge and contradictory scientific views (Chapter 7). Ferro and Nicolosi do not share this opinion. On the one hand, they see the TPD as a welcome example of European law-makers' attention to a new sector, where it is necessary to establish a balance between market rules and other objectives. On the other, they believe that the TPD borrows excessively from the tobacco control regulatory repertoire, thus bypassing the opportunity to set up a truly innovative regulatory regime (Chapter 8). This sentiment is also shared by Kovacevic in Chapter 10. The position taken by $\mathrm{Wu}$, Lin, and Lo is just the opposite: they prefer a total ban combined with the pharmaceutical model for e-cigarettes with therapeutic claims (Chapter 9). Gartner and Bromberg are probably somewhere in the middle (Chapter 11).

Obviously it is not possible to summarize here all the details of the analyses presented in the individual chapters. For the purposes of this introduction, the editor selected two specific issues that appear to be particularly interesting, to wit: (i) the factors behind the choice of a specific regulatory model for e-cigarettes; and (ii) the extent of regulatory freedom enjoyed by regulators under the applicable international and supranational rules.

Since science remains inconclusive as to the risks and benefits of e-cigarette use, other factors have to play a role in determining the shape of the regulatory regime applicable to these products. ${ }^{27}$ It seems that the normative stance held by key decision-makers within a country (or other important public figures able to influence the regulatory process in this specific area) on how to optimally deal with the tobacco epidemic is particularly important. If these people see it mainly as a problem of nicotine (rather than tobacco addiction), and believe in the effectiveness of current tobacco control methods (which will ultimately lead to the eradication of the tobacco problem rather than its replacement with nicotine addiction), or are deeply suspicious (rightly, by the

27 See an interesting observation by Professor Stanton A. Glantz on the recent study concerning the gateway effect: "This result shows that the gateway of e-cigarettes in Great Britain is about four times as powerful in Great Britain, where health authorities have embraced e-cigarettes, more than in the US (where most health authorities have been skeptical of e-cigarettes), where the odds of youth who initiate with e-cigarettes progressing to smoking are 'only' tripled." S.A. Glantz, "Strong evidence for a huge gateway effect for e-cigs in Britain, even stronger than in USA" (Centre for Tobacco Control Research and Education, March 7, 2018) https://bit.ly/2SPBrGr accessed January 15, 2019. 
way) of any initiatives that come from the tobacco (or, more broadly, nicotine) industry, it makes little sense for them to support this new technology. On the other hand, if key players are predominantly interested in the harm reduction approach and/or are skeptical about the efficiency of existing tobacco control measures, they may be more willing to embrace an e-cigarette friendly regulatory approach. Chapter 11 indicates that this factor was relevant in shaping the Australian approach to e-cigarettes.

History also matters. Past positive experiences with harm reduction policies may constitute an incentive for regulatory experimentation with e-cigarettes. Conversely, past failures in the implementation of harm reduction strategies (or limited experience with such policies) will push countries in the opposite direction. Again, Australia-as discussed in Chapter 11-seems to confirm this, while the UK is probably on the other side of the spectrum.

The political strength of various actors whose interests are directly and indirectly affected by e-cigarette regulations can also play a significant role. Such actors include users and their associations (both formal and informal). If the consumer base is large enough, as the EU case study attests (see Chapter 7), they can more easily translate their expectations into political claims and put pressure on relevant decision-makers (which also means that it might be more difficult to introduce a strict regulatory regime in those countries that have established strong markets for e-cigarettes). ${ }^{28}$ Other groups that can also influence the regulatory process include not only the e-cigarette companies, but also the tobacco and pharmaceutical industry. The first of these was initially rather hostile to e-cigarettes, considering them a disruptive technology (as explained in Chapter 2), but since then has gradually embraced this new market niche by creating its own products and/or taking over its competitors. This means that the tobacco industry could take different strategic positions depending on the point in time. For example, it was in favor of extending the US Food \& Drug Administration's (FDA) authority to e-cigarettes, ${ }^{29}$ but against the recent sales ban that was introduced by Hong Kong (see also the discussion in Chapter 9 on the tobacco industry's influence on the regulatory process in China). ${ }^{30}$ Pharmaceutical companies also have interests in restricting the sales of e-cigarettes, as those products potentially constitute competition to

28 Of course, this assumes a certain quality of the regulatory process, which is a characteristic feature of democratic regimes. In authoritarian and quasi-authoritarian states, this factor (at least as far as users are concerned) is less relevant.

29 J.H. Adler et al, "Baptists, bootleggers \& electronic cigarettes" (2016) 33(2) Yale J Regul 313, at 348.

${ }^{30}$ L. Du, D. Wei, "Hong Kong bans e-cigarettes in latest blow for Big Tobacco" (Bloomberg, October 10, 2018) https://bloom.bg/2AKkplN accessed January 15, 2019. 
the nicotine replacement therapies (NRT) they market. ${ }^{31}$ This consideration was highlighted by the European Commission in the context of its initial TPD proposal. According to the Commission, e-cigarettes enjoyed an unjustified advantage, undermining the level playing field as compared to NRT products. There is also evidence that some pharmaceutical companies lobbied against the "light touch" approach to e-cigarettes during the TPD legislative process (again, see Chapter 7 for more details).

There also seems to be some cross-learning between countries (an issue not addressed in this volume). The introduction of a specific regulatory regime in one state may sometimes lead to its spread to neighbors or even more distant countries, without any real internal discussion as to the rationality of specific regulatory solutions or their fitness to the local conditions. ${ }^{32}$ Certain countries - as well as their domestic institutions - occupy a privileged position in this context, acting as norm makers rather than norm takers. This may be a consequence of, among other things, their political and cultural strength, their epistemic and technical superiority, or the importance of their market for other countries. The FDA seems to be such an institution. In the context of e-cigarettes its influence is highlighted by several countries' decisions to ban e-cigarettes following the FDA 2009 import alert (66-41) concerning e-cigarettes (directing US Customs and Border Protection to reject their entry into the country on the basis that they were unapproved drug delivery devices), as well as the subsequent FDA report that found diethylene glycol and certain carcinogens in examined e-liquids. Shortly after, bans were introduced in Argentina, Brazil, Colombia, Panama, Saudi Arabia, and the United Arab Emirates. Some of those countries explicitly referred to the 2009 FDA position as a justification for their strict approach to e-cigarettes. ${ }^{33}$

31 N. Fides, "Glaxo boss bemoans rise of vaping" (The Times, January 17, 2015) https://bit.ly/2H8shmW accessed January 15, 2019. The statistical figures appear to confirm that fear (at least in the UK), as there seems to be a correlation between the rise of e-cigarettes and a sharp decline in NRT sales (see for example R. West, E. Beard, J. Brown, "Trends in electronic cigarette use in England" (Smoking Toolkit Study, 2018) http://smokinginengland.info/latest-statistics/ accessed January 15, 2019.

32 For more on the process of the diffusion of law, see W. Twining, "Diffusion of law: a global perspective" (2014) 36 JLP 1.

33 See for example Panama: Y.G. Mojica, "Advierten sobre cigarillos con veneno" [Warning about cigarettes with poison] (La Prensa, October 22, 2009) https://bit. ly/2VO6ap9; Argentina: Administracion Nacional de Medicamentos, Alimentos y Tecnologia Medica, Disposicion 3226/2011: Prohibese la commercialiacion y usi en todo el territorio nacional de un determinado product [Prohibits the sale and use throughout the national territory of a certain product] https://bit.ly/2SRdGxJ; and Brazil: N.V. Eich, "Anvisa pró́be comercialização do cigarro eletrônico" [Anvisa prohibits the commercialization of electronic cigarettes] (Estadao, August 31, 2009) https: //bit.ly/2D74gJ0, all accessed January 15, 2019. 
The activities of the FCTC COP also appear to affect the choice of a specific regulatory model for e-cigarettes. As noted above, both the FCTC COP and the Secretariat have endorsed a total ban as one of the legitimate regulatory options available to states (alongside a regulatory regime that would aim at addressing specific risks posed by these products). It seems that Taiwan, despite not being a party to the Convention, was inspired by the strict approach promoted by both bodies (see Chapter 9). The adoption of the FCTC was also indicated as one of the reasons behind the need to reform the EU regulatory framework for tobacco and tobacco-related products. Moreover, in the Pillbox 38 (UK) Ltd judgment the CJEU referred not only to the Convention but also to one of the COP decisions, noting that it recommended the consideration of specific restrictions for e-cigarettes (for example with regard to advertising and sponsorship) and the monitoring of their use (for more details see Chapter 7). Other countries which have decided to regulate e-cigarettes, or even banned these products, sometimes also refer to the FCTC documents. What seems to be interesting is that these documents can serve as a basis for completely different regulatory actions (which, as discussed in Chapter 4, is the result of the uncertain status of ENDS under the Convention and the lack of clear guidance from the COP).

Sometimes domestic legal norms (including constitutional ones) and internal political constraints may also have an impact (at least temporarily) on the shape of the regulatory model applicable to e-cigarettes in a specific country. Two case studies analyzed in this volume may serve as an example. The FDA's unsuccessful attempt to assert its jurisdiction over e-cigarettes in 2009 (as drug devices), and the court proceedings that ensued, delayed the FDA regulation by a few years and enabled the creation of an e-cigarette market in the US (see Chapter 10). A similar situation occurred in the EU. The prolonged process surrounding the adoption of the TPD stalled regulatory activities with respect to e-cigarettes at the national level in some Member States, effectively freezing the existing regulatory environment (ranging from complete prohibition to a laissez-faire model) (Chapter 8). More recently, Switzerland's Federal Administrative Court has overturned a ban on the sale of electronic cigarettes with nicotine, finding it incompatible with the existing applicable laws. ${ }^{34}$

The contributing authors have also confirmed that the extent of regulatory freedom enjoyed by regulators in this policy space is determined not only by national laws (for example constitutional norms), but also by international

34 "Court overturns Swiss ban on e-cigarettes" (Swissinfo, April 28, 2018) https: //bit.ly/2FqWtrA accessed January 15, 2019. Various e-cigarette restrictions were also challenged in other jurisdictions, such as Mexico, the Netherlands, Germany, and Estonia. 
obligations and, in the case of the EU, by the relevant treaty rules and general principles of European law. This means that it is not possible to investigate and fully understand the regulatory activities of states with respect to e-cigarettes without analyzing the relevant applicable international and supranational rules.

Intuitively, one would think of the FCTC as an international treaty which constrains states' autonomy in regulating e-cigarettes by imposing certain common standards. However, as explained in detail in Chapter 4, a careful analysis of its text reveals that this is not the case. It seems that it is entirely up to the Parties of the Convention how they classify e-cigarettes for the purposes of the FCTC. They may interpret the conventional notion of "tobacco products" broadly, thus bringing e-cigarettes within the purview of the FCTC, or opt for a narrow interpretation and remove those products from the scope of most of FCTC obligations. Another option for the Parties is to rely on Art. 5.2(b) of the FCTC, which requires implementation of effective measures for preventing and reducing tobacco consumption, nicotine addiction, and exposure to tobacco smoke. As explained in Chapter 4, the formulation of this provision is sufficiently broad to cover e-cigarettes. However, this provision leaves the Parties with an almost unlimited discretion as to their choice of a preferred policy. Within this discretion a particular Party may decide to classify e-cigarettes, at the national level, as tobacco products, medicinal products, or simply ordinary consumer goods. It may also decide to entirely prohibit their sales and use. Of course, it is also always possible for the Parties to classify e-cigarettes at the national level as they wish, even without any reference to the Convention. Consequently, a particular Party may decide on its own regulatory framework for e-cigarettes, as well as on the classification of those products, by simply using its inherent sovereign powers. Thus, from the legal point of view the Convention does little to constrain its State Parties.

In Chapter 5, Gispen and Veraldi look at international human rights law as a relevant international framework which does not merely guide states when designing their e-cigarette regulatory regimes, but may actually restrict their regulatory autonomy in this field. In particular, State Parties to human rights treaties must protect and promote the health of individuals, especially children. This means that there is a positive obligation for states, under the right to health, to discourage (but not necessarily ban) the use of harmful substances (such as nicotine); to regulate industries that produce these products; and to actively inform individuals about the harmful effects of their use in proportion to the risks they pose. When marketed with therapeutic claims (as harm reduction tools), e-cigarettes should be required to conform to the relevant medical laws. An additional layer of complexity emerges if e-cigarettes are identified as gateway products. In such a case, a set of supplementary requirements will be activated, ranging from the obligation to regulate the use of e-cigarettes at places where children congregate, to additional advertising restrictions. 
In Chapter 6, Foltea and Mercurio identify the WTO system as potentially relevant when determining the scope of the regulatory freedom enjoyed by states. As they correctly note, international trade rules that are concerned with discrimination may have the potential to be pertinent to an assessment of complete bans on e-cigarettes in a situation wherein traditional combustible products remain legally available on the market. In this context, they argue that there are sound grounds to conclude that both categories of product are either similar or likely to be considered as such in the future (depending on the development of science and the market situation), and therefore they should receive identical regulatory treatment under WTO rules. If such treatment is not provided, countries need to ensure that their e-cigarette bans are supported by sufficient scientific justification and that they constitute the least trade restrictive alternative available. The authors also indicate that similar problems may emerge with respect to other regulatory measures applied at the national level to e-cigarettes in situations where there are no equivalent restrictions for traditional combustible products. This group particularly includes bans on the registration and use of intellectual property linked to e-cigarettes, display bans, or indoor vaping bans.

As shown in Chapters 7 and 8 , the supranational rules applicable in the context of the EU can restrict the freedom of individual Member States as well as European law-makers. In principle, until the adoption of the TPD, Members were free to regulate e-cigarettes as they considered appropriate. This resulted in a great variety of regulatory approaches, potentially undermining the establishment of the internal market for this category of products. Since this situation was qualified as an internal market problem rather than a public health protection issue, it fell within the scope of shared (and not supporting) competences. This means that since the adoption of the TPD, Member States can exercise their competences only with respect to those issues that are left unregulated by the Directive or other pieces of EU law (for example, excise taxes on e-cigarettes or the regulation of flavors). This has obviously circumscribed their regulatory freedom and completely changed the regulatory landscape in Europe. The EU rules, however, are also relevant for decision-makers at the European level. The EU legal system is of a constitutional character and establishes a clear hierarchy of norms. Secondary EU law (for example, directives and regulations) needs to be compatible with the provisions of the founding Treaties as well as the Charter of Fundamental Rights of the European Union. In the context of the TPD, this particularly meant that EU law-makers had to comply with: (i) the principle of subsidiarity, which provides that the Union can take action only if and to the extent that the objectives of the intended action cannot be sufficiently achieved by its Member States and if, due to the scale or effects of the proposed action, the objective can be better achieved at the EU level; (ii) the principle of proportionality, which stip- 
ulates that an adopted measure cannot exceed the limits of what is appropriate and necessary in order to achieve a particular objective set out in the Treaties; (iii) the principle of equal treatment, which means that comparable situations cannot be treated differently, and different situations should not be treated in the same way unless such treatment is objectively justified; and (iv) the EU's fundamental freedoms (here the right to property and the freedom to conduct a business). Although the TPD has been ruled to have passed all the applicable legal thresholds, these principles also mark out the future parameters of the regulatory freedom enjoyed by the EU regulators.

\section{WHAT TO EXPECT IN THE FUTURE?}

As was mentioned above, the field is subject to dynamic changes of a scientific, regulatory, and market character. As far as the first category is concerned, it should be stressed that in recent years e-cigarettes have attracted growing interest from the scientific community (with a corresponding increase in available funding). Consequently, many of the leading universities currently host research teams that work on various aspects of their use, and a number of major research reports (including those which are based on clinical studies) are expected in the upcoming years. ${ }^{35}$ They may shed new light on our current assumptions, determining more clearly the risks that are connected with e-cigarette use (as well as their extent), the efficiency of e-cigarettes as a cessation method, or broader societal consequences of their presence on the market. If sufficiently conclusive, they may affect the direction of regulatory policies taken by states, either by making them more restrictive or more liberal.

When it comes to regulatory developments, probably the most important was the FDA's decision to restrict sales of flavored e-cigarette products in order to limit their availability and use among minors. The agency announced in November 2018 that such products will be sold only in age-restricted in-person locations, with online sales subject to tightened age verification procedures. The FDA also promised to strengthen its enforcement efforts against those retailers that violate age restrictions on the sale of e-cigarettes. ${ }^{36}$ This may not be its final word: initially it planned to completely ban sales of flavored e-liquids (except for mint and menthol) in all convenience stores

35 See for example the list of ongoing research projects at Clinical Trials (US National Library of Medicine) https://bit.ly/2C8g77N accessed January 15, 2018 (indicating almost 100 active projects relating to e-cigarettes).

36 FDA, "Statement from FDA Commissioner Scott Gottlieb, M.D., on proposed new steps to protect youth by preventing access to flavored tobacco products and banning menthol in cigarettes" (November 15, 2018) https://bit.ly/2CatNyX accessed January 15, 2019. 
and gas stations in the US. ${ }^{37}$ Some individual American states are also active in this area. For example, California is currently working on a total ban on all retail sales of flavored e-liquids. ${ }^{38}$ Some other states, or countries, may follow suit and introduce various restrictions on flavored e-cigarette products in the future. This issue may become relevant during the next meeting of the Conference of the Parties, which is scheduled for 2020.

While on one side of the Atlantic the regulatory regime is becoming more restrictive, on the other side it may soon be relaxed. The UK government is planning to review the current rules applicable to e-cigarettes (to a great extent determined by the $\mathrm{TPD}^{39}$ ) after the country leaves the EU, as is currently planned for 2019. ${ }^{40}$ This is in reaction to the House of Commons Science and Technology Committee's report on e-cigarettes, published in August 2018, which pictured e-cigarettes not as a risk but rather as "an opportunity to significantly accelerate already declining smoking rates" and proposed "a shift to a more risk-proportionate regulatory environment; where regulations, advertising rules and tax duties reflect the evidence of the relative harms of the various e-cigarette and tobacco products available."41

Regulators are also busy in other parts of the world. For example, China has recently banned the sale of e-cigarettes to minors, ${ }^{42}$ and is contemplating the introduction of certain additional restrictions (note that the market here is currently largely unregulated) ${ }^{43}$ It is not clear, however, what this reform will ultimately look like, or whether it will actually materialize. New Zealand, after liberalizing its e-cigarette market, is also planning to tighten the applicable laws by introducing a ban on the use of e-cigarettes in public places and

37 L. McGinley, "FDA plans curbs on e-cigarette sales over concerns about surge in teen vaping" (The Washington Post, November 8, 2018) https://wapo.st/2GXiXC3 accessed January 15, 2019.

38 J. McDonald, "California lawmakers will introduce a statewide flavor ban" (Vaping360, November 30, 2018) https://bit.ly/2sgXOJ7 accessed January 15, 2019.

39 For a detailed discussion of EU rules see Chapter 7 in this volume.

40 Department of Health \& Social Care, The Government Response to the Science and Technology Committee's Seventh Report of the Session 2017-19 on E-cigarettes (December 2018) Cm 9738.

${ }^{41}$ House of Commons Science and Technology Committee, E-cigarettes (Seventh Report of Session 2017-19, August 17, 2018) HC 505.

42 L. Zhang, "China: central government bans sale of e-cigarettes to minors" (Global Legal Monitor, September 19, 2018) https://bit.ly/2ARo1CT accessed January 15, 2019.

$43 \mathrm{Z}$. Yu, "Cities mull ban on e-cigarettes in public even though China is the biggest producer" (Global Times, November 7, 2018) http://globaltimes.cn/content/1126288. shtml accessed January 15, 2019. For a more detailed discussion of the Chinese approach to e-cigarettes see Chapter 9 in this volume. 
restricting their display at points of sale. ${ }^{44}$ In another example of a country that has recently taken a more restrictive approach, Israel is planning requirements of plain packaging for all e-cigarette products and restrictions on their advertising. ${ }^{45}$

The most significant event in terms of market development was probably the purchase of a 35 percent stake in JUUL Labs, Inc. (JUUL), for US \$12.8 billion, by Altria Group, Inc. (Altria) — one of the biggest producers of combustible tobacco products in the US. This is apparently part of Altria's business solution to the emergence of the post-tobacco world (particularly understandable if one considers the difficulties it faces in getting FDA approval for its IQOS system). ${ }^{46}$ For JUUL this was probably a way to expand its customer base (for example, the company will gain access to Altria's marketing and distribution channels, and Altria will allow JUUL to advertise its product to smokers in the form of package inserts in cigarettes), as well as a way to face the regulatory challenges that have emerged recently as a consequence of the various FDA actions. ${ }^{47}$ Not surprisingly, the transaction was met with heavy criticism from those in public health circles. For example, Matthew L. Myers, President of the Campaign for Tobacco-Free Kids, said that this was "a truly alarming development for public health and brings together the two companies that have been the most successful in marketing their highly addictive products to kids." 48 Another observer also alarmingly noted " $[\mathrm{t}]$ his move signals that vaping has now crossed a Rubicon. No longer the nemesis of big tobacco, it has become big tobacco." 49

Another important market development is the expansion of JUUL outside of the US. Initially, the company marketed its products (based on a pod system) only to American consumers, but in 2018 it started to offer its products in

44 D. Caruana, "New Zealand moves to tighten vaping laws" (VapingPost, November 26, 2018) https://bit.ly/2RFGXhi accessed January 15, 2019.

45 L. Bauer, "Israel to paint cigarette, e-cigarette packages with world's ugliest color" (CTech, January 1, 2019) https://bit.ly/2H4YGL1 accessed January 15, 2019.

46 See the discussion in Chapter 2 on the strategy of transforming big tobacco companies into quasi-pharmaceutical corporations and regaining the influence over regulatory processes as a legitimate socially engaged actor.

${ }_{47}$ S. Kaplan, M. Richtel, "Juul closes deal with tobacco giant Altria" (The New York Times, December 20, 2018) https://nyti.ms/2A5Xvoz accessed January 15, 2019.

48 Campaign for Tobacco-Free Kids, "Altria-Juul deal is alarming development for public health and shows need for strong FDA regulation" (Statement of Matthew L. Myers, December 20, 2018) https://bit.ly/2PQlsWc accessed January 15, 2019.

49 D. Marcus, "Why the Marlboro Man just bought a big chunk of Juul" (The Federalist, December 21, 2018) https://bit.ly/2CUSuRD accessed January 15, 2019. 
several other countries, notably in the UK, Ireland, and Canada. ${ }^{50}$ In the near future JUUL is planning to expand its operations further to the rest of the EU, Russia (where it has already an operative webpage), Indonesia, and other Asian countries. ${ }^{51}$ Considering the popularity of JUUL products in the US (as well as the dynamics of the company's growth), one may expect its entrance into new countries' markets to have a significant effect, potentially attracting a lot of new customers (current smokers, but arguably also fresh users).

The twentieth century was, in the phrase famously coined by Professor Allan M. Brandt, a cigarette century. Will the current one be an e-cigarette century? If a world without nicotine is not possible, this indeed may be the case. For better or for worse.

50 Note that in some countries JUUL has encountered some serious regulatory obstacles. For example, in Israel, almost immediately after entering the market, import and sale of its products was prohibited. The government cited the high level of nicotine concentration as reason behind the ban. "Israel bans Juul e-cigarette, 'a grave danger to public health"' (The Times of Israel, August 22, 2018) https://bit.ly/2RjNvTy accessed January 15, 2019.

51 F. Potkin, C. Kirkham, "Juul sounds out Indonesia for expansion, other Asian countries in its sights" (Reuters, November 13, 2018) https://reut.rs/2qFAeoC accessed January 15, 2019. 